\title{
The emergence of an educational tool industry: Opportunities and challenges for innovation in education
}

\author{
D. Foray ${ }^{\mathrm{a}, *}$, J. Raffo $^{\mathrm{b}}$ \\ a College of Management, EPFL, 1015 Lausanne, Switzerland \\ b WIPO, chemin desColombettes, 1211 Geneva 20, Switzerland
}

\section{A R T I C L E I N F O}

\section{Article history:}

Received 29 June 2012

Received in revised form

24 November 2013

Accepted 25 April 2014

Available online 5 August 2014

\section{Keywords:}

Tool industry

Educational tool

Innovation in education

\begin{abstract}
A B S T R A C T
The paper addresses two issues. One concerns the general conditions and procedures involved in the emergence of a tool industry. Tool industries emerge and evolve as a collection of capital goods and tool inventors and manufacturers. One of our goals is to use some of the works on historical cases to build a heuristic framework concerning the main conditions for the emergence and development of tool industries. The other issue is more factual and involves the question whether a tool industry is today emerging in the area of education. The paper describes the emergence of a population of firms specialised in developing and commercialising educational tools and instructional technologies and discuss whether this trend can be seen as part of the solution to the innovation deficit and cost disease problems in this sector?
\end{abstract}

(C) 2014 Elsevier B.V. All rights reserved.

\section{Introduction}

This paper is about innovation in education. Educational innovation is the act of creating and then diffusing new educational tools, as well as new instructional practices, organisations and technologies. Innovation is not research. It is (often) based on research and the advance of knowledge and consists of changing processes and practices in order to improve the quality and productivity of the service that is delivered. Achieving an education sector in which valuable innovations are constantly generated and efficiently used and managed is a major challenge to "re-invent" public education and find solutions to the so-called "Baumol's disease."1

The paper addresses two issues. One concerns the general conditions and procedures involved in the emergence of a tool industry in relation to an industry using the tool industry's output. Tool industries emerge and evolve as a collection of capital goods and tool

\footnotetext{
* Corresponding author at: College of Management, Station 5, EPFL, 1015 Lausanne, Switzerland. Tel.: +41216930035.

E-mail address: Dominique.foray@epfl.ch (D. Foray).

1 Many years ago, Baumol introduced an interesting distinction between progressive and non-progressive sectors. Non-progressive sectors are those in which productivity growth is limited, very sporadic and far smaller in magnitude than what is happening in the progressive part of the economy (Baumol and Bowen, 1965; Baumol, 1967). Such a productivity gap between two kinds of sectors gives rise to Baumol's (or cost's) disease. Education has always been considered by experts as a paradigmatic example of a non-productive sector (Roza, 2008; Hill and Roza, 2010).
}

inventors and manufacturers and, while they may originate in one industry, often involve the creation of new industries specialised in the production of tools, a process of industrial dis-integration. There are many historical cases of such processes of emergence and growth - the machine-tool industry of course (Rosenberg, 1963), but also some more recent cases such as chemical engineering (Arora et al., 2001) or the biotech tools companies (Henderson et al., 1999; Cockburn, 2003). One of our goals is to use some of the works on these cases to build a heuristic framework concerning the main conditions for the emergence and development of tool industries. The other issue is more factual and involves the question as to whether a tool industry is today emerging in the area of education. What is the economic significance of the emergence of a population of firms specialised in developing and commercialising educational tools and instructional technologies? To what extent are these tools being take up and used within the education sector? This will be the empirical part of the paper. As regards our empirical research strategy, it is useful to stress that one of the major challenges associated with the study of educational innovation is the lack of data. Studies of technological innovations traditionally focus on R\&D spending and patenting as well as on innovation data that are collected through surveys of firms. These measures are unlikely to be satisfactory for addressing the broad issue of innovation in education. However, the goal of our paper is not to address this broad issue but to study and characterise the emergence and opportunities for growth of an 'educational tool' industry. For such a purpose, the use of patent data to measure innovations in tools is relevant. 


\section{The economic fundamentals of the emergence of a tool industry}

Steinmueller (2006) observes that the emergence of several historical examples of tools industry involves the delocalisation of knowledge, at least in part from the production of the good or the delivery of the service. This delocalisation is accompanied by a shift in knowledge 'holding' and the emergence of a new site of knowledge accumulation, the tool producer. Prior to the emergence of a tool industry, a much greater degree of expertise among the individuals engaged in production activities can be observed. These are the people with specific knowledge of the tools and procedures being employed on the factory floor. But as a machine-tool industry emerges, and, with it, companies and factories without machinists - the technician who is capable of rebuilding the machinery or the tool - a vast body of specialised knowledge disappears from the site of use and reappears at the other site - the capital good or tool producer. After the emergence of the tool industry, the production operations are comparatively 'de-skilled', involving a relocation of learning and knowledge towards the new tool producers.

A direct consequence of this process is the development of new (to the industry) forms of co-ordination based on producer-user relationships. $^{2}$

\subsection{Conditions for tools industry's emergence}

Steinmueller identifies several general conditions that explain in what kind of socioeconomic circumstances a tool industry is likely to emerge.

One general condition is to be found in the works of Smith, Young or Stigler: the division of labour is limited by the size of the market. Widespread markets for producer goods and tools ensure that the design and manufacture of these tools is increasingly remote from the site of production.

Another important condition is the increasing application of a 'systemic approach' to the problems of increasing the productivity and standardisation of industrial or service outputs. The process of relocation of the specialised knowledge regarding tool production outside the factory or company that produces the final good allows companies to produce generic and multipurpose machines and tools that replace the specialised tools developed within specific firms. Functional specialisation creates a feasibility space for the generalisation and standardisation of the technologies and tools of production.

These two forces - functional specialisation and the development of generic tools - foster the dynamics of the tool industry evolution.

\subsection{Conditions for tools industry's development}

Beyond general conditions (technology and market opportunities, firm size diversity, appropriability conditions and the production and availability of the needed industry-specific public goods), relevant for any industry (not necessarily a tool industry), two specific issues have to be addressed.

One important issue deals with the ability of the downstream companies (those which no longer have tool production and design capabilities and skills) to exploit the opportunities offered by the newly formed tool industry. In his historical examination, Steinmueller (2006) highlights the tensions involved in adopting the American System of Manufacture - a system of standardised

\footnotetext{
2 The role of interactions between tool producers and users in the development of tool industries has been particularly stressed and studied by Rosenberg (1963) as well as Carlsson (1984).
}

parts that can be efficiently produced by the emerging machine tool industry with great economies of scale and efficiency. Some companies (and managers) resisted this change and preferred to continue using craft methods and skilled workmen to produce and 'fit' the components of a product and so missed the opportunity offered by the new tool industry.

Secondly, the emergence of a new tool industry in a given sector of activity involves the transformation of the industry structure towards a higher degree of vertical disintegration. This leads to the appearance of a kind of new tool market, which necessarily makes coordination much more dependent on a complex web of contractual arrangements. To what extent this web of contractual arrangements is manageable - i.e. it does not cause an explosion of transaction costs - is a key point for the sustainable development of the new industry (this was a cause of great inefficiencies in the case of the biotech tool companies (Cockburn, 2003)).

Such a new - more vertically specialised - structure has certain efficiency properties. Cockburn (2003) for instance identifies three factors of efficiency gains:

- Specialisation: although large integrated firms minimise some costs, they can raise others. New specialised firms are likely to be faster and more cost effective at developing tools. Specialisation and focus probably give new tool producers major cost advantages in doing certain kinds of things.

- Market-driven resource allocation: large integrated firms can slow down progress because of the incentives to shelve or abandon new technologies in order to avoid cannibalising existing techniques.

- Intensified competition: a socially costly practice is generated by large integrated firms that invent new tools and keep them as trade secrets. Knowledge spillovers and social returns are likely to be lower than if they are disclosed through market relationships (perhaps patent and licenses).

But realising these efficiency properties requires strong conditions. In general, as Cockburn suggests (2003), one can be optimistic about efficiency being raised by increased vertical specialisation in industries where:

- Competition is high among horizontal segments

- Specialisation reduces costs

- Vertical coordination is relatively unimportant

- Tool prices reflect marginal costs

- Bargaining and contracting are easy and effective.

To summarise this part, the emergence and development of a tool industry involves a process of vertical specialisation. The efficiency outcome of the new structure is uncertain, depending both on the way the efficiency properties of vertical specialisation are realised and on the way potential inefficiencies of the new tool market are minimised. Within this framework we will proceed to the empirical analysis of the emergence of a tool industry in the education sector.

\section{A first look at innovation in education}

"American schools are integrating instructional technology into conventional K-12 classrooms at a glacial pace" (Guthrie, 2007) The education sector is often characterised by experts as a sector suffering from an innovation deficit and a structural inability to advance instructional technologies and practical knowledge and know-how regarding pedagogy at the same rate as what is 
occurring in some other sectors. "Consider the efforts to develop more effective educational practices in schools: even if we do know more about educational practices that we did previously, knowledge creation in this domain has been slow and there have been severe difficulties in diffusing 'new and superior' knowledge" (Nelson, 2003, p.915).

Talking of an innovation deficit in the case of the education sector is difficult because of the problem of empirical observation (already mentioned). But another difficulty is due to the fact that it is simply hard to define and measure innovation in a context where the goals and objectives of the activity are not well defined and where the very concept of education as an activity that aims at achieving certain types of objectives is not tight: it lacks transparency, verifiability and broad consensus. ${ }^{4}$

In an industry where the main economic goal is for instance productivity improvement, we can quite easily derive what the innovations are. In the case of education, innovation definition is an issue. What are the goals? Is it to teach and reach more children, more potential learners or is it to teach them how to think creatively and independently? Different goals will require different types of innovation. For example, it is obvious that the so-called technologies of the "massive open on-line courses" (MOOCS) that are currently taking off have the potential to dramatically alter the relation between the inputs of instructors designing and delivering content and the output as measured by exposure to this content, one possible measure of educational productivity. It is rather unclear, however, whether these will be more successful at teaching students to think more creatively or will overcome gaps between the receipt of instructional content and its internalisation as learning. From these alternative understandings of productivity, it is far less clear what productivity MOOCS will have.

This article cannot be the locus for an in-depth discussion of the goals and objectives of education, a discussion with many different dimensions and that should call for interdisciplinary thinking. This is why it is perhaps better to leave the definition of innovation somewhat open. We propose therefore to take the expression of "innovation deficit" in the sense of a general phenomenon of stagnation in the ways educational services are delivered at any level (primary, secondary, etc.) and whatever goals or objectives are placed at the centre of the system. "That a class in 2013 resembles a lecture from 2300 years ago" (Thomson, 2011) illustrates this point in a rather anecdotal style. Although experts in the 60s or 70s predicted the rapid fall of the traditional delivery system (the classroom, the teacher and the pupils) because of the advent of the computer and the IT revolution - "I think the computer will blow up the school. That is the school defined as something where there are classes, teachers running exams, people structured in groups by age, following a curriculum" (Seymour, 1999) - this did not really happen. This long-term blockage in the technologies and organisational structures of the delivery system is the main symptom of either innovation deficit or innovation failure within the education sector. ${ }^{5}$

The emphasis on innovation deficit and failures in the delivery processes creates some similarity between the education case and another case, which is healthcare. David Cutler (2010) in particular makes the same kind of diagnosis and asks similar questions about the innovation deficit in the latter sector.

\footnotetext{
3 Technical knowledge involves in this case the broad set of both embodied and disembodied knowledge that enable the development of pedagogical practices and instructional technologies.

${ }^{4}$ We borrow the notion of tightness from Mokyr (2004).

5 Tyack and Cuban (1995) have provided an in depth documentation and analysis of the moderate pace of change in educational practices in the case of the U.S. public school system during the whole $\mathrm{XX}^{\circ}$ century.
}

Before investigating what has changed rapidly during the most recent period - the formation of a population of specialised suppliers that are entering the market for educational tools in order to offer new solutions to the delivery problem - we can summarise some of the most frequently identified and discussed factors of the innovation deficit in the education sector.

\subsection{A difficult science and a poor link to practices}

The main problem is the difficulty of developing a science that can illuminate practices and provide guidance for their systematic improvement (Foray, 2001, 2006, 2011). Formal R\&D is of secondary importance both for the training of people and the generation of useful innovation. What Murnane and Nelson (1984) wrote more than 25 years ago concerning education is still by and large true - educational R\&D is very weak in producing practical solutions. In a more recent paper, Bryk (2007) argues that educational R\&D generates too rarely knowledge of immediate value for solving problems and developing applications. ${ }^{6}$ There will of course continue to be contributions to education from social science theory. However, the goal of this kind of research is not to provide and develop a repertoire of reliable practices and tools to solve immediate problems that teachers meet daily in their professional life: "For novice teachers, practical problems in classrooms are not usually perceived to be solvable by drawing upon the psychology of education or child development, that have been studied in universities" (Foray and Hargreaves, 2003, p.12).

This problem of a very weak link between science and the improvement of practices is crucial since it influences both the supply of and the demand for research; and this creates a fundamental inertia in the system caused by the negative externalities that exist between a weak supply and an insufficient demand.

There are three factors explaining the poor role of science in illuminating practices in education:

- On the supply side, educational sciences are just very hard to do. Berliner (2007) wrote about educational research as the hardest science: "we do our science under conditions that physical scientists would find intolerable". Compared to designing a bridge, the science to help change schools and classrooms is harder to do because context cannot be controlled and inherent lack of generalisability across contexts reduces the value of any research method to illuminate a body of practices. ${ }^{7}$ There is indeed an educational science but nothing like an applied science or engineering discipline to develop a body of knowledge and techniques that could illuminate educational practices. This is an argument that has been forcefully developed many times and again very recently by Nelson $(2003,2013)$

- On the demand side, most practitioners who are (or should be) involved in the improvement of practices do not believe that the educational problems they are facing in the course of their professional life can be solved by inquiry, by evidence and by science (Elmore, 1996). They do not believe according to Elmore (2002), that it is necessary to have a developmental theory of how students learn and how the pedagogy relates to the development

\footnotetext{
${ }^{6}$ Bryk (2007) suggests two explanations for this failure: first, most education research is carried out in universities that place priority on individual contributions to new knowledge and this is detrimental to the formation and development of larger scale, and collaborative efforts. Second, the academic culture and incentives are not conducive to 'engineering work' that is needed to produce practical innovations useful to schools.

7 See the special issue of EINT (Foray et al., 2007) about the comparison between educational research and research in the biomedical area. Cooke and Foray (2007) describe the US policy experience in developing an education science through the development of experimental research capacity.
} 
of knowledge and content. Weak incentives for teachers to use research are rooted in a deep cultural norm - that teaching is an individual trait: the foundation of the performance involves natural quality, inspiration, talent and not a set of competences acquired over the course of a career (Elmore, 1996). Because of this cultural norm, it is very difficult to make a case for knowledge management, building databases about evidence on "what works" and encouraging teachers to behave as engineers by searching for solutions to problems in case books (Foray and Hargreaves, 2003).

- Finally, there is a general deficiency of incentives to codify technical knowledge and knowhow and the resources allocated to codification are weak. Numerous practices remain tacit, not explicated and not articulated, invisible and difficult to transfer. "There is no more in education than a weak equivalent in the field of pedagogical knowledge to the systematic recording and widespread use of cases found in surgery or law and the physical models in engineering and architectural practice. Such records coupled with comments and critiques of experts allow new generations to pick up where earlier ones left off" (Foray and Hargreaves, 2003, p.12). Some important mechanisms to support the cumulative nature of knowledge and materialise the potential for spillovers are simply missing. When excessive stocks of knowledge are left in tacit forms, this makes them more costly to locate, to appraise and to transfer. A result may be excessive insularity and waste of resources resulting in the underuse of the existing stock of knowledge. This may therefore create private and social inefficiencies.

\subsection{Translating increasing pressures about performance into innovation}

To put it in Nelson's words, the key to success in advancing technical knowledge has been the designing of practice around what is known scientifically. For various reasons, this key is not operating well in education.

As a result, policy makers, industries and society as a whole are asking schools to make improvements in the presence of an extremely weak technical core. "Consider what would happen if you were on an aeroplane and the pilot came on the intercom as you were starting your descent and said, "I've always wanted to try this without the flaps". Or if your surgeon said to you in your pre-surgical conference, "you know, I'd really like to do this way I originally learned how to do it in 1978". Would you be a willing participant in this? People get sued for doing that in the "real" professions, where the absence of a strong technical core of knowledge and discourse about what effective practice is carries a high price" (Elmore, 2002).

The problem not so much concerns the lack of incentives for schools and administrators to improve educational practices and technologies; these incentives are there, probably less powerful than in other sectors, but pressure for performance of schools, which is channelled through higher standards and accountability, is increasing and thereby creating such incentives. But the problem lies rather in the way practitioners, teachers and administrators try to respond to these incentives and pressures. The problem lies in the failure to translate such pressures into innovation, improved practices and the development of instructional knowhow and technologies. Practitioners do not try to improve practices by relying on a strong technical core of knowledge that should be available in case books and databases. Instead, they respond to the increased demand for accountability by changing structures; but changing structure does not change practices. As Elmore (2002) argues forcefully: people and schools pour an enormous amount of energy into changing structures and usually leave instructional practice (innovation) untouched.
Now, as the next section will show, only a short look at patent data provides us with a slightly different view of innovation in this sector. The evidence collected and discussed below are quite consistent with recent case studies showing a slow diffusion of ICTbased tools such as interactive whiteboards and their integration into classroom teaching since the mid-90s (Hennessy and London, 2013; Mercer et al., 2010).

\section{A small (innovation) explosion? ${ }^{8}$}

We now turn to the innovativeness of the educational tool industry from an empirical standpoint. This is not an easy task as information on innovative practices for this particular sector is anything but abundant. Most of the existing empirical work has tackled this from the demand point of view, notably in the use of ICTs in schools and universities (e.g. Enochsson and Rizza, 2009; McKinney et al., 2009; Hennessy and London, 2013). But assessing the supply of educational tools without imposing a priori a particular definition of the demand requires a more systematic approach. We will see below that this happens to shed light on the sector's dynamics that are worth taking into account in future research.

\subsection{Empirical evidence from patent data}

Therefore, we propose here to tackle the innovativeness of this industry by analysing the educational technologies reflected in patent documents. In accordance with Closa et al. (2010), we are particularly interested in those applications in the field of learning and teaching that fall under the international patent classification (IPC) subclass G09B. ${ }^{9}$ When looking at this subclass in any major patent database - e.g. PCT or EPO PATSTAT - it becomes clear that patent applications have increased dramatically since the early nineties in the domain of educational and teaching technologies (see Fig. 1 for an example using PCT data). Also a positive trend is found for these technologies as a share of the total production of technologies since the mid-90s until 2007, which shows that this traditional sector is exhibiting faster than average growth in technological terms, although followed by a steep decrease in $2007 .{ }^{10}$

It goes without saying that patent indicators have several limitations when used to measure innovation (Pavitt, 1985; Basberg, 1987; Griliches et al., 1988). The most relevant one with respect to our research is that not all innovations are necessarily patented, as firms may opt for other means of appropriation like trade secrets, among others. We argue that this limitation actually works in the sense of our reasoning, as it refers to a lower bound of the innovation activity in the sector. Certainly, if innovativeness in the educational tool industry were not significantly apparent, it would not pass the threshold of being visible in the patent data. In other words, if we can see some patent applications for educational technologies being filed, it probably means that there are many more innovative initiatives being developed out there.

Indeed, a more careful look at the patent data suggests that the growth documented in Fig. 1 is not only explained by large incumbents' strategic behaviours, as we can also observe the formation of a population of small firms specialised in the development of technological solutions to educational problems and issues. Fig. 2a shows the increasing number of firms that are developing

\footnotetext{
${ }^{8}$ This section relies on the combination, update and further development of previous research (see Foray and Raffo, 2011, 2012).

${ }^{9}$ See Box 1 for further technical definitions of education-related technologies and examples.

10 See Foray \& Raffo (2012) for statistics presenting cross-countries comparisons on patenting activities in education.
} 


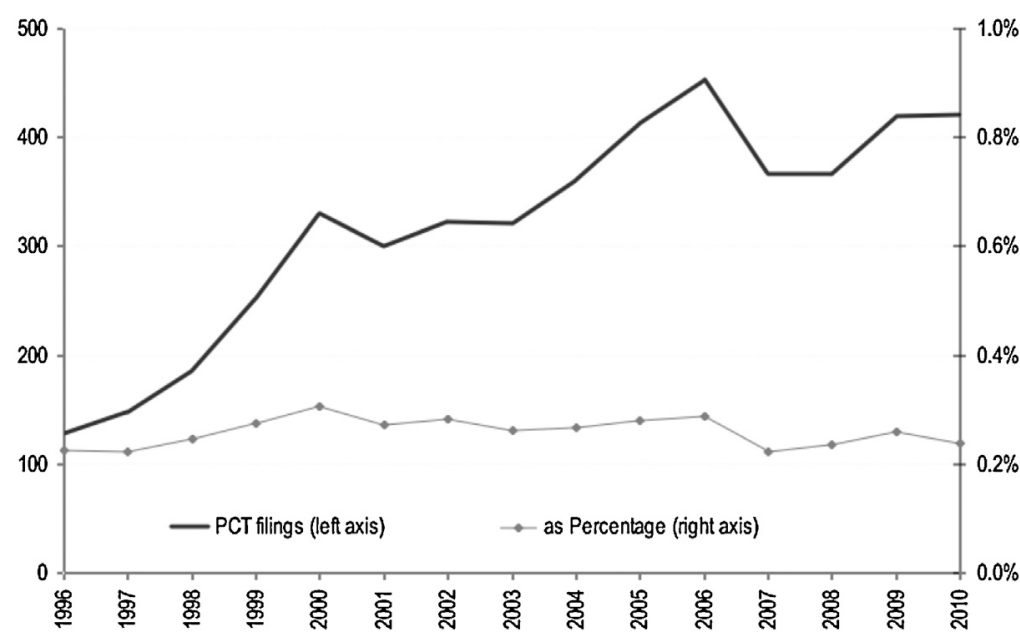

Fig. 1. Evolution of education-related technologies.

Source: WIPO Statistics Database (2013). Figures express PCT international applications declaring a G09B IPC subclass by priority year.

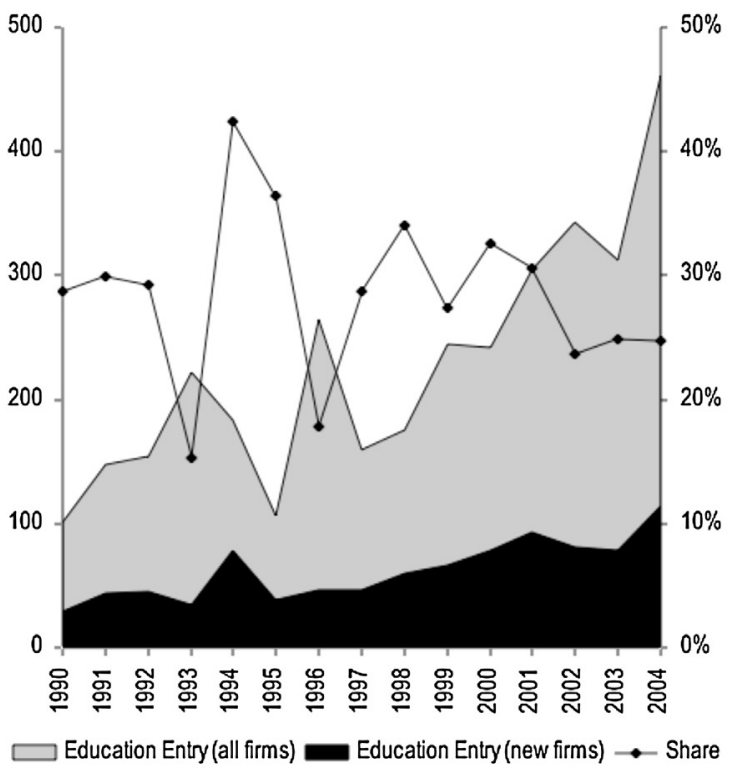

(a) Firms Entry

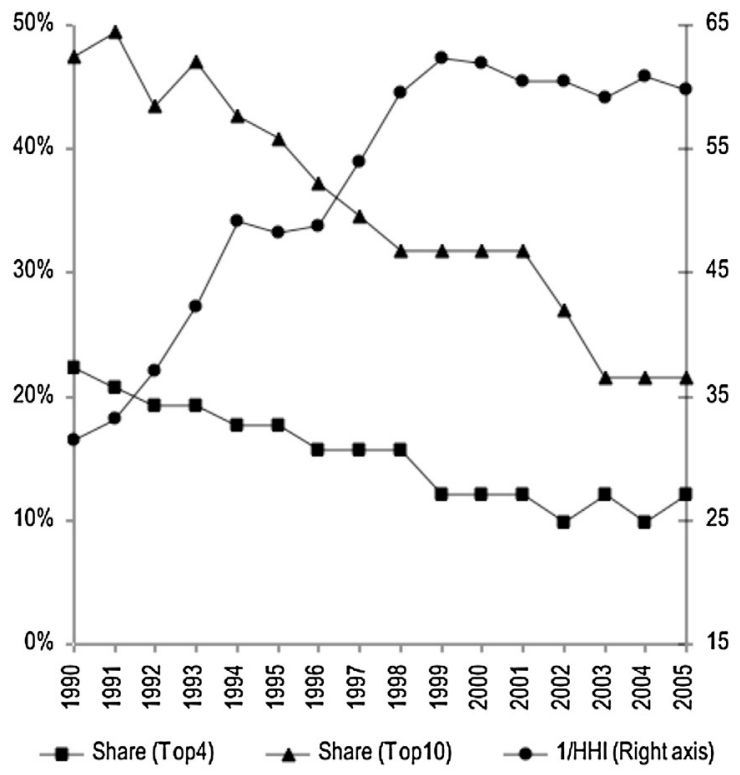

(b) Technological concentration

Fig. 2. Firms producing education-related technologies (Entry and Technological concentration).

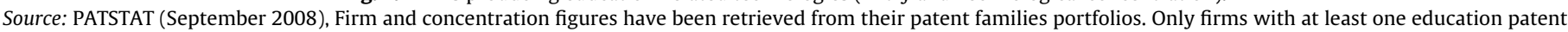
filed in EPO, JPO and USPTO are considered.

education-related technologies for the first time ("Education entry, all firms"), distinguishing the proportion of these that are filing a patent for the first time in any technological field ("Education entry, new firms"). In order to maintain the conservative approach mentioned above, we have only considered those firms with at least one education patent application filed in EPO, JPO and USPTO and we use the earliest priority year within the patent family as a proxy for technological entry. ${ }^{11}$ Given these rather restrictive criteria, we find that the broadly speaking 25-30 percent proportion of "new firms" in this sector is far from negligible. Moreover, the final list of applicants was checked both automatically and manually to

\footnotetext{
11 Please note that this latter assumption on the filing date needs not be related to the actual market introduction of the educational tool, as we are concerned here mostly by the creation of new specialized firms, not necessarily their success. In any case, there is evidence that market entry might not be always different from the patent application date (Pavitt, 1985; Basberg, 1987).
}

mitigate the risk of double counting. ${ }^{12}$ During this procedure, it was apparent that most of the applicants labelled as "Education entry, new firms" corresponded to this category.

This idea is reinforced by the declining (technological) concentration evidenced by different indicators displayed in Fig. $2 \mathrm{~b}$. There it can be observed that the concentration - expressed by both technological shares held by the top four and the top 10 firms - has been steeply declining over the past two decades. The inverse Herfindahl-Hirschman Index (HHI) furnishes a similar picture, showing that the technological concentration has been reduced from around thirty to sixty "ideal" firms. Furthermore, all three indicators suggest that this evidenced de-concentration might be slowing down or, if we consider the HHI, even regressing.

\footnotetext{
12 Please refer to Raffo and Lhuillery (2009), for more details on automatic name
} disambiguation. 
An interesting advantage of using patent data based on IPC categories is the fact that these can refer to either the function or the application of the technology. ${ }^{13}$ In other words, educational technologies falling into the G01B subclass can be broadly divided into those for which the application sector is the traditional education one - i.e. schools, universities, etc. - and those using educational technologies for other sectors not immediately related to the education one, like corporate training or educational leisure. Just a quick look at education-related patent applications - like the ones listed in Box 1 - confirms that examples of both kinds are easily found.

In order to dig deeper regarding this difference, we decided to investigate further the actual business activities of these educational patent assignees. Therefore we analysed a subset including all assignees having filed at least five educational patents in the USPTO for which their educational patents represented at least 30 percent of their total patent portfolio. ${ }^{14}$ This resulted in 54 companies that could be undoubtedly related to educational technologies, although not always having the public education system as their main market. Fig. 3 summarises the main markets targeted by these education-specialised companies. But it is worth noting that limits are sometimes blurred, as many of these companies will target their customers outside their usual environment. For instance, many of them offer educational products for children and young students, but they aim them for use during leisure time, notably with the help of their parents. Similarly, other companies offer advanced skills training through online applications or simulators, but sometimes they target the individuals directly and other times their employers.

In any case, these results suggest the emergence and consolidation of an industry specialised in the production of educational and instructional tools and knowledge with strong roots in new information technologies. A large part of this industry is made up of small and specialised firms.

\subsection{The development of instructional technologies in the wake of a great general-purpose technology}

The new information and communication technologies (ICTs) are clearly a source of innovation in the educational system: ICTs potentially offer a wide range of new tools and instruments to profoundly change the technological, organisational and institutional foundations of the sector considered. In this case, the development of ICTs provides opportunities to enlarge the repertoire of instructional technologies. The so-called process of co-invention of applications is no minor matter since it is the process by which the technology diffuses across a wide range of sectors and specific applications are generated (Bresnahan, 2010).

In fact, the characteristics of a general-purpose technology (GPT) are horizontal propagation throughout the economy and complementarity between invention and application development. Expressed in the economist's jargon, the invention of a GPT extends the frontier of invention possibilities for the whole economy, while application development changes the production function of one particular sector. The basic inventions generate new opportunities for developing applications in particular sectors. Reciprocally, application co-invention increases the size of the general technology market and improves the economic return on invention activities related to it. There are therefore dynamic feedback loops in accordance with which inventions give rise to the co-invention of applications, which in their turn increase the return on subsequent

\footnotetext{
13 See WIPO's Guide to the IPC (2012), p.20, para. 85.

14 It is worth noting that USPTO reports information on granted patents only until 2001, which means that five granted patents in the US represents a larger amount of applications both in the US and abroad.
}

\section{Box 1: Definition and examples of education-related patents}

Education-related patents are typically filed for products or devices that will be used in a training or education context, for training processes related to a specific set of skills (musical, medical, foreign language, reading, etc.) or for a general method that can be used in multiple educational settings. While many patents typically build on advances in information and communication technologies (ICTs) and propose some sort of simulators of real life practice, patents filed also concern objects or devices or tools that are not primarily ICT-based: card games to learn languages, mock-ups of chests, infant torsos, jaws, blood vessels or organs designed to practise specific medical techniques, teaching devices for some specific mathematical question, for example a device concerning Pythagoras' theorem demonstrating it arithmetically, geometrically and algebraically, or just a ruler to facilitate the learning of reading.

For practical purposes, we consider educational and teachingrelated technologies as any patent filed under the G09B IPC subclass, which is defined as Educational or demonstration appliances; appliances for teaching, or communicating with, the blind, deaf or mute; models; planetaria; globes; maps; diagrams. According to Closa et al. (2010), electronic learning and teaching applications are found under IPC class G09B. These applications are often built on a basis of general-purpose computers and include standard interfaces like keyboards, pointing devices, voice input and touch-sensitive displays used for interacting with the user. They also mention that the implementation of teaching concepts is often described on a very high abstract level, where the hardware infrastructure is assumed as being known to the expert and the software is presented in functional terms.

According to this definition a list of examples of titles of education-related patents published in 2010 is provided below for illustration purposes only (source: WIPO Patentscope, retrieved in May 2013)

ICT-based technologies

- Communication and skills training using interactive virtual humans (WO/2010/093780)

- Multi-user headset teaching apparatus (WO/2010/101890)

- Movable learning gaming machine using movable toy (WO/2010/147312)

- Adaptive teaching and learning using smart digital learning objects (WO/2010/086780)

- Pronunciation evaluating device and method (WO2010133072)

- Weakness finding system and method (WO/2010/109663)

- Methods and systems for assessing psychological characteristics (WO/2010/099443)

- Methods and systems for quantifying technical skill (WO/2010/108128)

- Apparatus and method for the lifelong study of words in foreign language (WO/2010/150986)

- Second language pronunciation and spelling (WO/2010/147769)

- Foreign language learning device (WO/2010/140258)

\section{Non-ICT-based technologies}

- Chinese character study book (WO/2010/131924)

- Method for learning vocabulary and the principles of English sentences through a card game (WO/2010/087658)

- Pythagorean teaching device (WO/2010/101451)

- Educational ruler for facilitating reading (WO/2010/096842)

- Young children's aid to quick counting (WO/2010/097563)

- Teaching aid for preschool education (WO/2010/120039) 


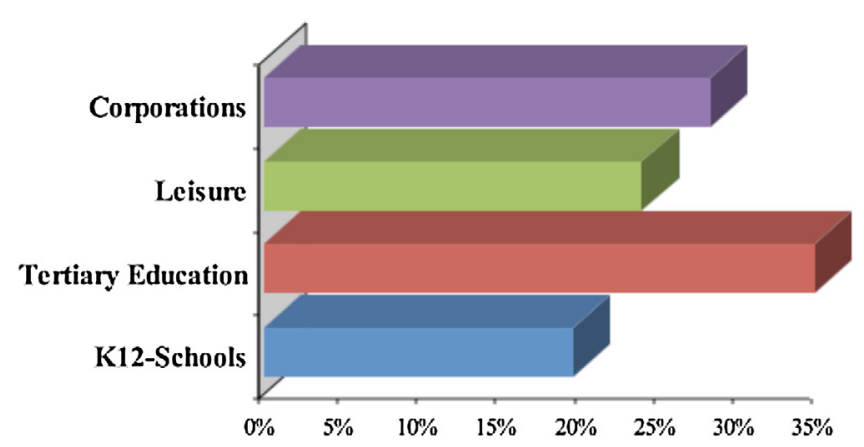

Fig. 3. Main targeted markets by innovative companies specialised in educational tools.

Source: Own research from PATSTAT (2008) applicant data, LexisNexis and institutional web profiles of companies.

inventions. When this process evolves favourably, a long-term dynamic develops, consisting of large-scale investments in R\&D whose social and private marginal rates of return attain high levels.

It seems that the renaissance of innovation in practices and methods of pedagogy and instructions is strongly associated with the dynamics of ICTs. The application of ICTs in education is not a single innovation, but an array of technologies that can be applied in a variety of ways (Murnane et al., 2002). ICTs are also viewed as enablers of change: schools engage in a series of activities that could not have been undertaken without ICTs. It is however premature to claim that the education sector has today reached the position of a central user sector with the potential to significantly boost the dynamics of ICTs.

The way the new ICTs are and will be exploited in the educational sector as a mechanism to profoundly transform the delivery process is very dependent upon the level of education, whether primary, secondary, tertiary or adult (continuing) education. Some of the biggest impacts of ICTs in changing organisations and structures of any activity involve the full realisation of the potential for remote access to a service as well as the possibility of 'consuming' the service in an a-synchronic way. However such potential is only fully realisable in contexts where the 'consumer' is endowed with sufficient capacity to be autonomous in conducting and managing their consumption activity. This is the case of course of students and learners at the tertiary and adult levels of education, but not at lower levels. This means for example that the MOOCS technologies have the potential to discard the classroom in the near future at the higher education level, but certainly not in elementary and secondary schools.

\section{Discussion}

Cutler (2010) began his study of the innovation deficit in the health sector by asking himself "where are the entrepreneurs?" Our own study provides a partial answer to this question in the case of the education sector.

\subsection{An emerging educational tool industry}

Quite intensive innovation activity regarding the development of new instructional tools and technologies is observable. However the locus of this activity is not really inside the sector but on the supply side. We observe the formation of a tool industry: a population of specialised firms that invent, design and commercialise educational tools. Such a process, as in any historical case of tool industry emergence, involves a process of delocalisation of knowledge - at least in part regarding the delivery of the educational service. There is a sort of shift in knowledge "holding" that involves the emergence of a new site of knowledge accumulation: the tool producer. Historically, one important reason for the emergence of a tool industry (beyond the classic reason of market size increase) is the increasing application of a systemic approach to the problem of increasing productivity of industrial or service outputs. The process of relocation of the specialised knowledge about tools outside the institution that delivers the final service (the school in our case) allows the production of generic and multipurpose machines and tools that replace the specialised tools formerly developed within each specific organisation delivering the service.

Historically, the formation, emergence and development of tool industries have often generated efficiency gains and economic growth through greater specialisation, intra-segment competition between tool producers and effective coordination between the tool companies and downstream organisations.

Given our observation and discussion of the innovation deficit in "the core" of the system (the classroom), it is good news that a growing population of entrepreneurs is entering the market for new educational tools. Companies competing to invent and commercialise tools are expected to play a great role in enhancing innovation and productivity in the downstream sector.

However there is a need to qualify this trend. One important concern is related to the ability of the public sector to exploit the opportunities offered by the emerging tool industry. Another concern is related to the increasing patenting activity necessary for small, specialised firms to enter and compete. This activity is likely to adversely affect static efficiency through the pricing of tools above marginal costs and the increasing negotiation and bargaining costs on this new market.

\subsection{Patent problems with the new structure}

The development of a market for instructional tools implies that potential users must pay for access to methods and knowledge that are explicitly priced in the form of licensing agreements. This opens to the question whether the potential benefits of new tools to improve educational methods may be limited by above marginal cost pricing that will impede access to innovation. We know that researchers in biomedical sciences are quite good at simply "ignoring" (in the sense of failing to comply with) patents on research tools (Walsh et al., 2000). And the firms that have been granted these patents either anticipate bad appropriability of their knowledge by granting licences on a large scale or simply tolerate infractions, especially by academic researchers. This set of norms and practices on both sides results in the fairly effective minimisation of the social inefficiencies that are potentially generated by the so-called anti-commons problem in biomedical research (Heller and Eisenberg, 1998). It is not clear whether school administrators and teachers are in the position to exhibit similar behaviour and what the strategic responses of the small, specialised firms holding the patents would be.

For example, the US patents of Blackboard "for technology used for Internet-based education support system and method", cover 44 different features that make up a learning management system. F. Lowney, Director of the IT management system at the Georgia College and State University Library, wrote: "Much of what Blackboard claims to have invented really came from and was freely given by the education community. Now the community is being punished through a gross lessening of competition in this market" (Networkworld, 2006). For an Associate Professor of Medical Education, the real question is: "What are they going to do next, try to patent word processing and charge you royalties if you are using it in a classroom? If obvious uses of technology to facilitate teaching based on standard software applications are allowed to be patented just because they are used to support education we are in real trouble" (Inside Higher Ed, 2006). The problem with Blackboard patents - and, we 
suspect, hundreds of patents for educational technologies - clearly involves the now common conflict between open source communities, which are proliferating in the educational world, and for-profit business attempting to enforce their claims on some (software) patents. And it is rather unclear that Blackboard (or any other companies of this kind) is able to enforce its patents in the face of open source alternatives. Sales and support are critical complementary assets to help these companies to overcome their appropriability problem.

Another problem with the vertically disintegrated structure concerns the ability of the small, specialised companies to capture the benefits of their innovation. Transaction and bargaining costs on these markets for pedagogical methods are likely to be very high; and patents as a means of capturing the value of the innovation might not be so effective (depending partly on how the first problem is going to be solved). The problems of the firms considered here are rather similar to what has been described by Cockburn (2003) with regard to the tool companies in the biotechnology sector.

\subsection{There is now a tool industry but for what market?}

Baumol has written extensively and convincingly on the role and crucial position of the entrepreneur or young innovative firms as a mechanism for fuelling innovation and an organisational form that is needed to complement the modes of operation of large companies. But the education sector has built severe barriers to entry making entrepreneurial activities in the sector sound not very attractive ${ }^{15}$ : the reward structure in this sector does not favour the competitive entry of new firms and radical innovators willing to take risks and be creative with the prospect of huge private return on R\&D and other innovation activities. Among those barriers can be mentioned (Berger and Stevenson, 2007) ${ }^{16}$ :

- The education sector does not invest in innovation.

- In many countries, there is a so called "big edu" - an oligopoly of a few very large suppliers of educational resources that solve the problem of a highly atomised demand by building an enormous sales force; entrepreneurs cannot afford to play this game.

- Slow sales cycles, involving too many people "in charge" at different levels (State agencies, districts, schools).

- The constraint of pilot programmes to test an innovative tool mean that start-ups cannot sell it on a scale that is economically viable.

- There is no business culture to manage innovation in the school system: administrators usually choose to solve problems by using in-house people more intensively because this costs nothing since the people are already paid for rather than buying new tools and systems. Few school administrators have a formal training in business decision-making or calculating return on investment.

- Teacher time is a sunk cost; there is no benefit to saving this time.

- It is very often recommended by public authorities that administrators should not meet with entrepreneurs and vendors to avoid any unfair advantages but with such a "vendor wall" in place, how can they be informed about anything?

\footnotetext{
15 This does not apply of course to the creation of textbooks. However one could ask whether a new textbook is an innovation. A new textbook can of course includes some technological and organizational innovations but, as any other new books, it does not represent an innovation by itself. Foray (2010) builds a taxonomy of the different kind of mediations between knowledge creation and the improvement of instructional practices. The creation of textbooks is one of these mediations while technological or organizational innovation is a different one (and the production of evidence from evaluation works is a third one).

${ }^{16}$ It is interesting to note that in his paper Cutler (2010) is developing similar arguments to explain entrepreneurial deficits and failures in healthcare.
}

- Because the various barriers described here constrain the size of potential returns, and educational companies require too long to obtain a meaningful return, no Venture Capitalist (VC) is interested and most innovative start-ups in this field fail to convince professional VCs to fund them. Angel investors can be a substitute to a certain extent.

- It is common in education that foundations and charities give away the very things that entrepreneurs are trying to turn into business! This unintended consequence of a strategy of building a commons is a phenomenon we also know well in development economics as killing entrepreneurial spirit.

Beyond all the problems identified above, the public sector of education is also a special market in the sense that "the consumers" do not necessarily want every year to buy a better product that a restless innovative activity needs to offer and commercialise.

So we are facing quite a disturbing puzzle: we observe some intensive innovation activities but the market sounds very hostile; so what are these entrepreneurs really doing? The solution to the puzzle is straightforward: these companies are targeting other markets than the K12 school sector: corporate education, education during leisure time, tertiary and vocational education are perhaps smaller markets but far more "entrepreneur-friendly". And in fact in-depth analysis of the top 50 companies specialised in patenting educational tools shows that very few are successful in commercialising their inventions in the K12 school systems. Most companies target the other markets (see Fig. 3).

\section{Conclusion}

Good news for education - a sector that exhibits notorious difficulties to generate and exploit innovations to improve practices - is that an educational tool industry has emerged; that is to say a population of small firms is inventing and commercialising instruction (mainly ICT-based) technologies. New sites of knowledge generation and accumulation have emerged: the tool producers.

However the main commercial target of these companies is not the huge K12 public school system. This market does not satisfy most conditions for attracting and sustaining a strong entrepreneurial activity in the tool business. The public school system seems not (yet?) able to exploit the opportunities offered by the development of a tool industry and there are still too many enemies of innovation in the public sector in terms of poor management practices, governance and culture, as well as funding and resource allocation logics.

But other "smaller" markets seem to be sufficiently attractive for entrepreneurs and this connection explains to a certain extent why we have observed the patent explosion and some increase in the number of firms specialised in the tool business.

An important question for further research is whether the invention of tools for corporate education and other "smaller" markets" has spillover effects in the sense of building user capabilities (in a very broad sense) in the large $\mathrm{K} 12$ education sector enabling this sector to progress in learning how to exploit the opportunities offered by the growing educational tool industry.

\section{Acknowledgements}

We gratefully thank the coordinators of this special issue Jackie Krafft, Sébastien Lechevalier, Francesco Quatraro and Cornelia Storz for their encouragement and guidance as well as three anonymous referees for their very useful comments and suggestions. At a later stage, Ed Steinmueller provided very detailed and precise comments and suggestions that have been extremely useful to prepare the final draft. We are very grateful to him. 


\section{References}

Arora, A., Fosfuri, A., Gambardella, A., 2001. Markets for Technology: Economics of Innovation and Corporate Strategy. MIT Press, Cambridge.

Basberg, B.L., 1987. Patents and the measurement of technological change: a survey of the literature. Research Policy 16 (2-4), 131-141.

Baumol, W., 1967. Macroeconomics of unbalanced growth: the anatomy of urban crisis. The American Economic Review 57 (3), 415-426.

Baumol,W., Bowen, W., 1965. On the performing arts: the anatomy of their economic problems. American Economic Review 55 (n1/2), 495-502.

Berger, L., Stevenson, D., 2007. K-12 entrepreneurship: slow entry, distant exit. In: American Enterprise Institute Conference on the Future of Educational Entrepreneurship, Washington, DC, October.

Berliner, D., 2007. Educational research: the hardest science of all. Educational Researcher 31 (8), 18-20.

Bresnahan, T., 2010. General purpose technologies. In: Hall, B., Rosenberg, N. (Eds.), Handbook in Economics of Innovation, vol. 2. North-Holland.

Bryk, A., 2007. Ruminations on reinventing an R\&D capacity for educational improvement. In: American Enterprise Institute Conference on the Future of Educational Entrepreneurship, Washington, DC, October.

Carlsson, B., 1984. The development and use of machine tools in historical perspective. Journal of Economic Behavior and Organizations 5, 91-114.

Closa, D., Gardiner, A., Giemsa, F., Machek, J., 2010. E-Learning. Patent Law for Computer Scientist. Springer, Berlin, Heidelberg, pp. 143-154.

Cockburn, I., 2003. O Brave New Industry that Has Such Patents in It! Reflections on the Economics of Genome Patenting, Draft. Boston University.

Cooke, T., Foray, D., 2007. Building the capacity to experiment in schools: a case study of the Institute of Educational Sciences in the US department of Education. Economics of Innovation and New Technology 16 (5), 385-402.

Cutler, D., 2010, May. Where are the Health care Entrepreneurs? The Failure of Organizational Innovation in Healthcare, NBER WP Series, $n^{\circ} 16030$.

Elmore, R., 1996. Getting to scale with good educational practice. Harvard Educational Review 66 (Spring (1)), 1-26.

Elmore, R., 2002. The limits of change. Harvard Education Letter January-February.

Enochsson, A., Rizza, C., 2009. ICT in Initial Teacher Training: Research Review, OECD Education Working Papers, No. 38. OECD Publishing.

Foray, D., 2001. Facing the problem of unbalanced development of knowledge across sectors and fields: the case of the knowledge base in primary education. Research Policy 30, 1553-1561.

Foray, D., 2006. The Economics of Knowledge. MIT Press, Cambridge (chapter 9).

Foray, D., 2010. Quelle écologie de la connaissance adaptée à une stratégie générale de perfectionnement des pratiques pédagogiques? Report Prepared for the Center for Educational Research and Innovation. OECD, Paris.

Foray, D., 2011. Educational Innovation: An Economist's Perspective. Rigour and relevance in Educational Research, The Research Council of Norway, Oslo.

Foray, D., Hargreaves, D., 2003. The production of knowledge in different sectors: a model and some hypotheses. London Review of Education 1 (1), 7-19.

Foray, D., Raffo, J., 2011. Structurally Non-progressive' Service Industries Need not Remain so for Ever: A Case Study on Education, Promoting Innovation in the Service Sector. United Nations-Economic Commission for Europe.

Foray, D., Raffo, J., 2012. Business-driven Innovation: Is it Making a Difference in Education? An Analysis of Educational Patents, OECD Education Working Papers, n 84. OECD Publishing.

Foray, D., Murnane, R., Nelson, R., 2007. Randomized trials of education and medical practices: strengths and limitations. Economics of Innovation and New Technology 16 (5), 303-306 (special issue).

Griliches, Z., Pakes, A., Hall, B., 1988. The Value of Patents as Indicators of Inventive Activity. NBER
Guthrie, J., 2007. Instructional technology and education policy. In: Conference on Advancing Knowledge and the Knowledge Economy. National Academy of Sciences, Washington, DC.

Heller, M., Eisenberg, R., 1998. Can patent deter innovation? The anticommons in biomedical research. Science 280, 698-701.

Henderson, R., Orsenigo, L., Pisano, G., 1999. The pharmaceutical industry and the revolution in molecular biology: interactions among scientific institutional and organizational change. In: Mowery, D., Nelson, R. (Eds.), Sources of Industrial Leaderships: Studies of Seven Industries. Cambridge University Press, Cambridge.

Hennessy, S., London, L., 2013. Learning from International Experiences with Interactive Whiteboards, OECD Education Working Papers, n 89. OECD Publishing.

Hill, P., Roza, M., 2010. Curing Baumol's disease: In Search of Productivity Gains in K-12 Schooling, CRPE White Paper n 2010_1. University of Washington.

Inside Higher Ed, 2006. Blackboard Patents Challenged. www.insidehighered.com/ news/2006/1201/patent

McKinney, D., Dyck, J.L., Luber, E.S., 2009. iTunes University and the classroom: can podcasts replace Professors? Computers \& Education 52 (3), 617-623.

Mercer, N., Hennessy, S., Warwick, P., 2010. Using interactive whiteboards to orchestrate classroom dialogue. Technology, Pedagogy and Education 19 (2), 195-209.

Mokyr, J., 2004. The Gift of Athena: The Historical Origins of the Knowledge Economy. Princeton University Press.

Murnane, R., Nelson, R., 1984. Production and innovation when techniques are tacit: the case of education. Journal of Economic Behavior and Organization 5, 353-373.

Murnane, R., Sharkey, N., Levy, F., 2002. A role for the internet in American education? In: The Knowledge Economy and Postsecondary Education. National Academy Press, Washington, DC.

Nelson, R., 2003. On the uneven evolution of human know how. Research Policy 32, 909-922.

Nelson, R., 2013. The limits of technological innovation, Dynamism and innovation in the West - has a decline set in? In: Center on Capitalism and Society at Columbia University, 11th Annual Conference, September.

Networkworld, 2006. Software Patent Ignites Firestorm in Education. www. networkworld.com/news/2006/11106-software-patent-ignites-firestorm-inhigher-education.html

Pavitt, K., 1985. Patent statistics as indicators of innovative activities: possibilities and problems. Scientometrics 7 (1), 77-99.

Raffo, J., Lhuillery, S., 2009. How to play the "Names Game": patent retrieval comparing different heuristics. Research Policy 38 (10), 1617-1627, http:// dx.doi.org/10.1016/j.respol.2009.08.001.

Rosenberg, N., 1963. Technological change in the machine tool industry 1840-1910. Journal of Economic History 23, 414-443.

Roza, M., 2008. Must public education suffer from Baumol's disease? The Denver Post (08.03.08).

Seymour, P., 1999. Vision for education. In: 91st Annual National Governor's Association Meeting in St. Louis Missouri, August 1999.

Steinmueller, W.E., 2006. Learning in the knowledge-based economy: the future as viewed from the past. In: Antonelli, C., Foray, D., Hall, B., Steinmueller, E.W.(Eds.), New Frontiers in the Economics of Innovation and New Technology. Edward Elgar.

Thomson, D., 2011. Is College (finally) ready for its innovation revolution?" The Atlantic www.theatlantic.com/business/archive/2011/05/is-collegefinally-ready-for-its-innovation-revolution/2393930/

Tyack, D., Cuban, L., 1995. Tinkering Towards Utopia: A Century of Public School Reform. Harvard University Press, Cambridge MA.

Walsh, J., Arora, A., Cohen, W., 2000. The Patenting of Research Tools and Biomedical Innovation. Science, Technology and Economic Policy Board of the National Academy of Sciences, Washington, DC. 